\title{
Local anaesthesia using Articaine and Lidocaine in oral and dental surgery: A comparative meta-analysis
}

\author{
M. K. Saggu ${ }^{1}$, H. Aga ${ }^{2}$, J. S. Saggu ${ }^{3}$, G. A. E. Burke ${ }^{2}$ \\ ${ }^{1}$ Maxillofacial Unit, University Hospitals Birmingham NHS Foundation Trust, Birmingham, UK \\ ${ }^{2}$ Maxillofacial Unit, Worcestershire Acute Hospitals NHS Trust, Worcester, UK \\ ${ }^{3}$ University of Liverpool, Liverpool, UK \\ Email: Manpreet.Saggu@uhb.nhs.uk
}

Received 19 December 2013; revised 24 January 2014; accepted 30 January 2014

Copyright (c) 2014 M. K. Saggu et al. This is an open access article distributed under the Creative Commons Attribution License, which permits unrestricted use, distribution, and reproduction in any medium, provided the original work is properly cited. In accordance of the Creative Commons Attribution License all Copyrights (C) 2014 are reserved for SCIRP and the owner of the intellectual property M. K. Saggu et al. All Copyright (C) 2014 are guarded by law and by SCIRP as a guardian.

\section{ABSTRACT}

Background: Articaine is an amide local anaesthetic, which is gaining popularity for use in dental and oral surgical anaesthesia in the United Kingdom. Hitherto there has been insufficient evidence to recommend articaine above the more commonly used lidocaine for dental procedures. The aim of this study is to compare the efficacy of $4 \%$ articaine with $1: 100,000$ adrenaline (4AA) with that of $2 \%$ lidocaine with 1:100,000 adrenaline (2LA) administered as buccal infiltrations for anaesthesia in mandibular permanent first molar teeth. Any significant advantage noted may obviate the need for regional blockage of the inferior dental nerve in dental or minor oral surgical procedure under local anaesthesia. Objectives: To review the published literature comparing the efficacies of 4AA and 2LA for achieving pulpal anaesthesia in human mandibular permanent first molar teeth. Null Hypothesis: 4AA and 2LA are of equal efficacy when used to anaesthetize mandibular permanent first molar teeth by buccal infiltration. Method: An electronic search encompassing Ovid MEDLINE®, PubMed (National Center for Biotechnology Information, US National Library of Medicine), SCOPUS ${ }^{\circledR}$, SCIRUS ${ }^{\circledR}$, EMBASE ${ }^{\circledR}$ databases and the Cochrane Library was performed to identify trials relating to the efficacy of 4AA and 2LA local anaesthetic solutions on mandibular first molars in adult participants. Study characteristics and outcome data were extracted as a basis for meta-analysis. Results: Three randomised controlled trials were identified for this meta-analysis. The relative efficacy of 4AA over $2 \mathrm{LA}$ in anesthetizing permanent first mandibular molars was calculated at $1.57(95 \% \mathrm{CI}=1.27$ to 1.95$)$. Conclusion:
Despite the promising results shown in the metaanalysis it is difficult to say from the evidence presented that 4AA should be used clinically in preference over 2LA.

\section{KEYWORDS}

Lidocaine; Articaine; Meta-Analysis

\section{INTRODUCTION}

Anaesthesia is a key component in the practice of dentistry. A range of local anaesthetic agents is widely available for use. Lidocaine is usually the anaesthetic of choice for most oral surgical procedures in the UK [1]; however, articaine has become increasingly available [2].

First introduced in 1976, 4\% articaine solutions have shown high levels of anaesthetic potency and low systemic toxicity in clinical situations, due to its pharmacological profile and physicochemical characteristics [3]. Regional nerves blocks and local infiltration are the most commonly used anaesthetic administration techniques for mandibular teeth; however, buccal infiltration anaesthesia of the mandibular first molar would be beneficial to both clinicians and patients in terms of the ease and comfort [4].

The preference of a local infiltration over that of regional block has previously been described. For the clinician, the ease and speed of administration would be beneficial to the anxious patient. It has also been suggested that there might be fewer risks in patients taking anticoagulant therapies. If a local infiltration of Articaine could provide more effective analgesia than Lidocaine then it might be a preferable analgesic for use in most routine dental procedures. 
The authors undertook this study to explore the possibility of using of Articaine (4AA) as a buccal infiltration alone to anesthetise mandibular first molar teeth, allowing dental, and some minor oral surgery procedures where surgical access is via the buccal cortex.

\section{OBJECTIVES}

To determine how effective buccal infiltration of 4AA is in producing mandibular permanent first molar pulpal anaesthesia when compared to 2LA.

\section{MATERIALS AND METHODS}

\subsection{Literature Searching}

The electronic databases of Ovid MEDLINE®, EMBASE ${ }^{\circ}$, PubMed ${ }^{\circledR}$, Scopus ${ }^{\circledR}$, Scirus ${ }^{\circledR}$ and Cochrane Central Register of Controlled Trials were interrogated to identify relevant citations of published trials. In order to identify relevant unpublished or on-going trials further searches of the metaRegister of controlled trials register was also investigated. Table A1 gives the details of the databases searched along with the search strategies used. Attempts were made to contact the leading manufacturer of articaine within the UK (Septodont ${ }^{\circledR}$ ) with regard to any information concerning on-going trials.

\subsection{Selection of Studies}

Randomised controlled trials (RCTs) fulfilling certain specified criteria were selected (Table 1). Cohort studies, case series and case reports are excluded from the review owing to the high potential for bias in these study designs. Case-control studies (except where nested as part of a cohort study) and economic evaluations are also excluded. Trials investigating the efficacy of buccal infiltrations of 4AA and 2LA administered to mandibular first molar teeth were included. A detailed list of the exclusion criteria is located in Table A2. The search process detailing the number of studies excluded at each point of the data collection is shown in Figure 1 and is detailed in Table A1.

\subsection{Data Abstracts and Study Characteristics}

The titles and abstracts obtained from the search were independently screened as suggested in the PRISMA protocol [5]. All obtained citations were checked to ensure that they fulfilled the inclusion criteria (Table 1). Those satisfying the criteria were then retrieved for analysis.

The data retrieved was extracted to Microsoft Excel ${ }^{\circledR}$ and included the authors, year of publication, study design, sample size, age range, intervention details with regards to the type of anaesthetic used and the measures of effectiveness were recorded (Table 2). The data detailing the time of onset and duration of onset of the anaesthetic were recorded; the data recorded for anaesthetic success was extracted. The data was analysed using StatsDirect ${ }^{\circledR}$.

The assessment criteria according to COHORT [6] and individual study rating can be located in Table A3. All of the studies stated that appropriate approval and consent of participants was taken.

\section{RESULTS}

Studies published between 1946 and the present were included within the meta-analysis. The author and a review team screened 177 citations. Data from three randomised controlled trials were included within the statistical analysis (Tables 2 and 3).

The relative efficacy of articaine when compared to lidocaine was calculated for each of studies included (Table 3) and used to obtain the synthesis value (Table 4). This is best illustrated by the forest plot (Figure 2). Therefore, the relative efficacy of 4AA over 2LA in anesthetizing permanent first mandibular molars was calculated at 1.57 (95\% CI $=1.27$ to 1.95$)$.

Cochrane's Q and $\mathrm{I}^{2}$ values were calculated from the raw data. Although though no significant heterogeneity was seen in the forest plot a random effects model was employed for the analysis due to the small number of relatively small studies included (as shown in Figure 2).

Table 1. Criteria for selection of studies included in meta-analysis.

\begin{tabular}{|c|c|}
\hline Criteria & Definition \\
\hline Study characteristic & $\begin{array}{l}\text { Randomised controlled trials, and controlled trials investigating the efficacy of buccal infiltrations of } 4 \% \\
\text { articaine } 1: 100,000 \text { adrenaline and } 2 \% \text { lidocaine } 1: 100,000 \text { adrenaline. }\end{array}$ \\
\hline Participant characteristics & Studies of participants aged of 18 or older. \\
\hline Intervention characteristics & $\begin{array}{l}\text { Studies with only infiltrations to mandibular permanent first molar teeth delivered by manual buccal } \\
\text { infiltration. }\end{array}$ \\
\hline Outcome characteristics & $\begin{array}{l}\text { Any clinical outcome, including anaesthetic efficacy by measuring sensory threshold to Electronic Pulp } \\
\text { Testing (EPT) measuring no response to maximal stimulation }(80 \mu \mathrm{A}) \text {. } \\
\text { Studies providing raw numbers of the effect measures or prevalence. } \\
\text { - Providing information of the sample size and age group, outcome variables and mean values. }\end{array}$ \\
\hline
\end{tabular}




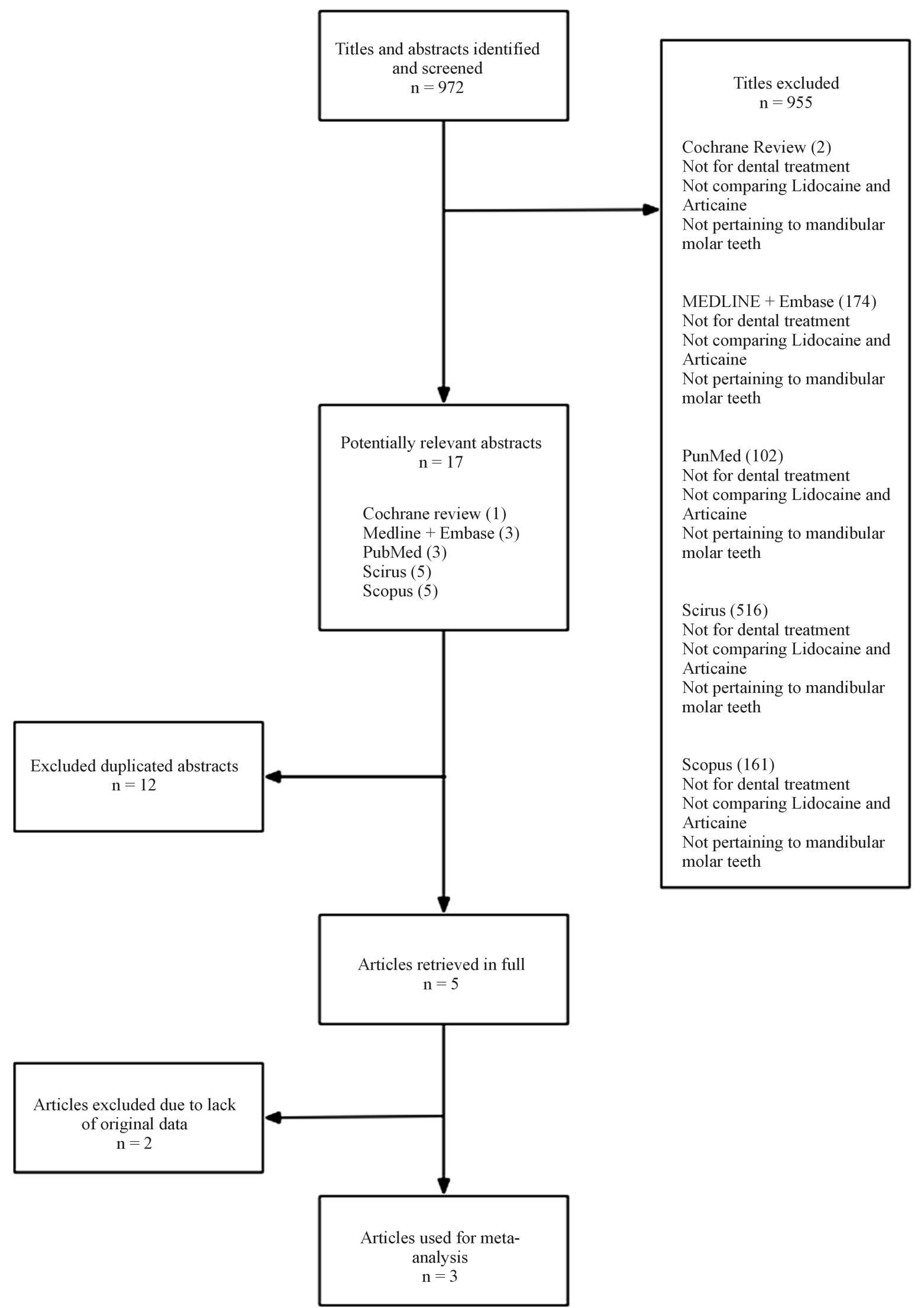

Figure 1. Search process flow diagram. 
Table 2. Summary of trial characteristics.

\begin{tabular}{|c|c|c|c|}
\hline Author & Abdulwahab et al. [7] & Robertson et al. [8] & Kanaa et al. [9] \\
\hline Year & 2009 & 2007 & 2006 \\
\hline Age group & $18-53$ & $19-51$ & $20-30$ \\
\hline Mean age & 24.9 & 27 & 22.8 \\
\hline Prospective (Y/N) & $\mathrm{Y}$ & Y & $\mathrm{Y}$ \\
\hline Randomised (Y/N) & $\mathrm{Y}$ & $\mathrm{Y}$ & $\mathrm{Y}$ \\
\hline Blinded (Y/N) & $\mathrm{Y}$ & $\mathrm{Y}$ & $\mathrm{Y}$ \\
\hline Cross-over (Y/N) & $\mathrm{Y}$ & $\mathrm{Y}$ & $\mathrm{Y}$ \\
\hline Sample size & 18 & 60 & 31 \\
\hline Anaesthetic dose & $0.9 \mathrm{ml}$ & $1.76 \mathrm{ml}$ & $1.8 \mathrm{ml}$ \\
\hline Outcome variable & No response EPT $(80 \mu \mathrm{A})$ & No response EPT $(80 \mu \mathrm{A})$ & No response EPT $(80 \mu \mathrm{A})$ \\
\hline Agent used & Lidocaine $2 \%$ 1:100,000 adrenaline & Lidocaine $2 \%$ 1:100,000 adrenaline & Lidocaine $2 \%$ 1:100,000 adrenaline \\
\hline Mean value & $3(16.7 \%)$ & $34(57 \%)$ & $12(38.7 \%)$ \\
\hline Agent used 2 & Articaine $4 \%$ 1:100,000 adrenaline & Articaine $4 \%$ 1:100,000 adrenaline & Articaine $4 \% 1: 100,000$ adrenaline \\
\hline Mean value & $7(38.9 \%)$ & $52(87 \%)$ & $20(64.5 \%)$ \\
\hline$p$ value & 0.001 & 0.0001 & 0.008 \\
\hline Induction & Injected over 30 seconds & Injected over 25 seconds & $0.9 \mathrm{ml} / 15$ seconds \\
\hline EPT testing & Testing every minute for 20 mins & Testing every 3 mins for 60 mins & Testing every 2 mins for 30 mins \\
\hline
\end{tabular}

Table 3. Extracted data for meta-analysis.

\begin{tabular}{|c|c|c|c|c|c|}
\hline Author & Year & Lidocaine success (event) & Sample size (lidocaine group) & Articaine success (event) & Sample size (articaine group) \\
\hline Abdulwahab et al. [7] & 2009 & 3 & 18 & 7 & 18 \\
\hline Robertson et al. [8] & 2007 & 34 & 60 & 52 & 60 \\
\hline Kanaa et al. [9] & 2006 & 12 & 31 & 20 & 31 \\
\hline
\end{tabular}

\section{DISCUSSION}

\subsection{Key Findings}

This meta-analysis suggests that the anaesthetic efficacy of 4AA when used as a mandibular buccal infiltration is greater than that of $2 \mathrm{LA}$.

\subsection{Biological and Clinical Interpretation}

Though the mechanism for the increased efficacy of articaine is not fully understood, Skjevik et al. [10] have suggested that Articaine exhibits an exceptional effectiveness in bone tissue penetration along with an additional unique lipophilicity switch in its ability to form an intra-molecular hydrogen bond.

Many studies have investigated articaine buccal infiltration anaesthesia and its application with regards to maxillary and incisor teeth $[11,12]$. While some have re- ported no significant difference between the use of articaine or lidocaine [13] many maintain that 4AA is more effective than 2LA in achieving pulpal anaesthesia. Additionally, the onset of pulpal anaesthesia with articaine has been shown to be significantly faster than Lidocaine via buccal infiltration $(\mathrm{P}=0.03)$, with a significantly longer duration of soft tissue anaesthesia (3.8 h vs. 2.5 h; $\mathrm{P}<0.0001)[14,15]$.

\subsection{Limitations}

The included studies are based upon the use of 2\% lidocaine with 1:100,000, adrenaline (epinephrine) whereas the most commonly used formulation for dental and oral surgical procedures in the UK employs adrenaline at the slightly higher concentration of 1:80,000. The concentration difference in vasoconstrictor may well account for a difference in clinical soft-tissue anaesthesia time mean- 


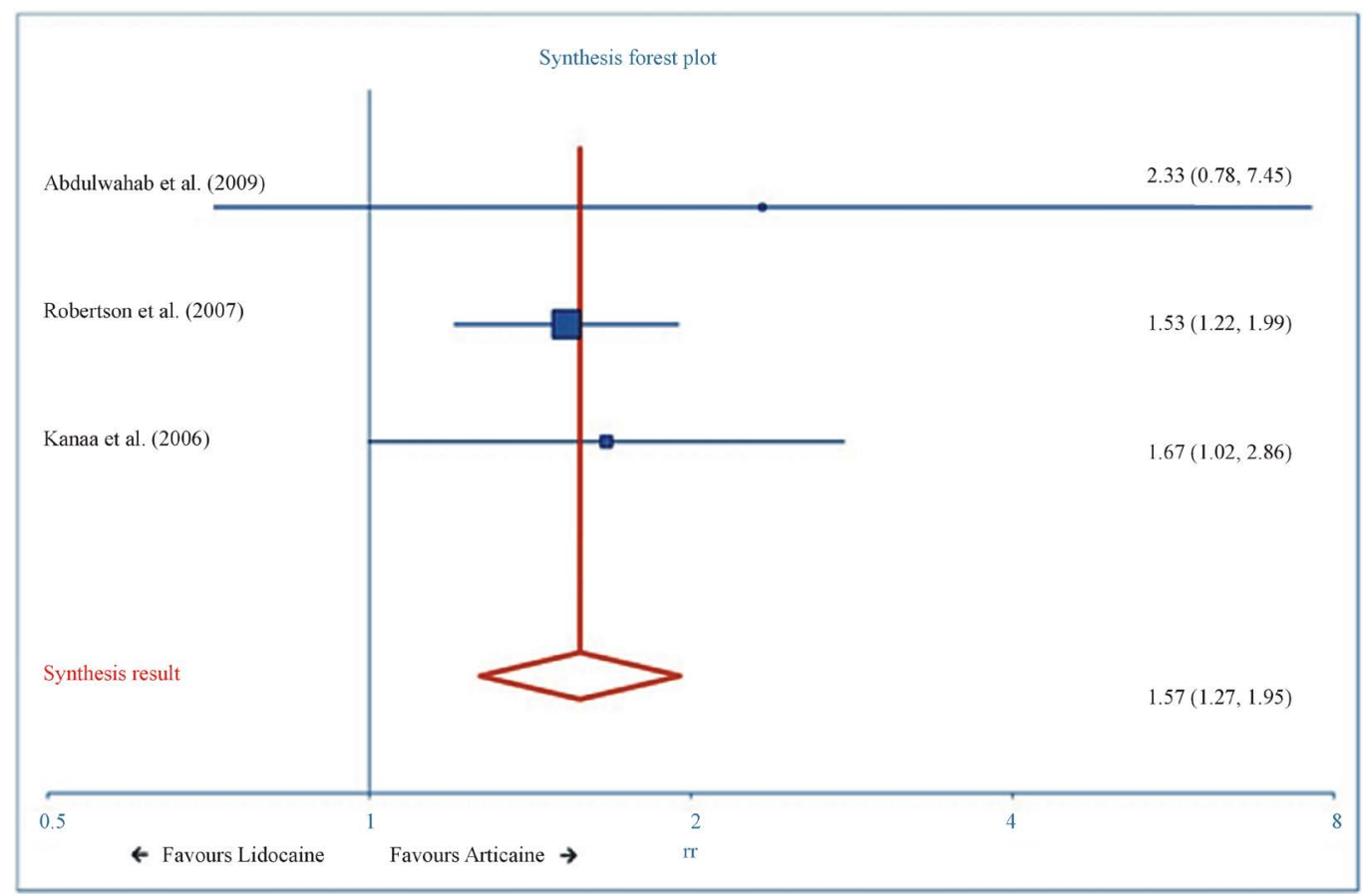

Figure 2. Relative risk meta-analysis forest plot (random effects).

Table 4. Comparison of relative efficacy between studies.

\begin{tabular}{|c|c|c|c|}
\hline \multirow{2}{*}{ Authors } & \multirow{2}{*}{ Relative risk } & \multicolumn{2}{|c|}{ 95\% CI (Koopman) } \\
\hline & & Min & Max \\
\hline Abdulwahab et al., 2009 [7] & 2.33 & 0.78 & 7.44 \\
\hline Robertson et al., 2007 [8] & 1.53 & 1.212 & 1.99 \\
\hline Kanaa et al., 2006 [9] & 1.67 & 1.02 & 2.86 \\
\hline Synthesis result ${ }^{*}$ & 1.57 & 1.27 & 1.95 \\
\hline
\end{tabular}

*Random effects model. Non-combinability of studies: Cochran $\mathrm{Q}=0.57$ $(\mathrm{df}=2) \mathrm{P}=0.7512, \mathrm{I}^{2}$ (inconsistency) $=0 \%(95 \% \mathrm{CI}=0 \%$ to $72.9 \%)$.

ing that the use of 4AA may make little difference in this aspect.

The trials included in the meta-analysis all considered pulpal anaesthesia to have been achieved following the absence of response to the maximal stimulation $(80 \mu \mathrm{A})$ with the electronic pulp tester on two or more episodes of testing. These results may not be directly transferable to oral surgical procedures such as the extraction of teeth which require anaesthesia of the structures surrounding the tooth.

As only a limited number of trails were available for inclusion within this meta-analysis it is premature to suggest that buccal infiltrations of 4AA in the mandibular region should be the anaesthetic agent and technique of choice.

\subsection{Comparison to Previous Work}

A meta-analysis conducted by Katyal, [16] investigating the efficacy and safety of articaine versus lidocaine in dental treatments supports the argument that articaine is more effective then lidocaine in providing anaesthetic success in the first molar region. Although higher pain scores for delivery were recorded, articaine has still been suggested as superior for use as an anaesthetic agent in dental treatment.

\section{CONCLUSION}

In this study 4AA has been shown to have greater efficacy in achieving pulpal anaesthesia in mandibular permanent first molar teeth than 2LA when administered via buccal infiltration on analysis of three studies. The increase in efficacy may be as high as 1.57 . The small numbers of available studies in this analysis indicate that more work is required before the results can be directly translated into clinical practice.

\section{ACKNOWLEDGEMENTS}

I would like to thank Mr S. Parmar (Consultant in Oral and Maxillofacial Surgery) for his contribution to this work.

\section{REFERENCES}

[1] Moore, P.A., Nahouraii, H.S., Zovko, J.G. and Wisniewski, S.R. (2006) Dental therapeutic practice patterns in the U.S. I. Anesthesia and sedation. General Dentistry, 54, 92-98.

[2] Yagiela, J.A. (2004) Recent developments in local anesthesia and oral sedation. Compendium of Continuing Edu- 
cation in Dentistry, 25, 697-706.

[3] Malamed, S.F., Gagnon, S. and Leblanc, D. (2001) Articaine hydrochloride: A study of the safety of a new amide local anesthetic. The Journal of the American Dental Association, 132, 177-185. http://dx.doi.org/10.14219/jada.archive.2001.0152

[4] Corbett, I.P., Kanaa, M.D., Whitworth, J.M. and Meechan, J.G. (2008) Articaine infiltration for anesthesia of mandibular first molars. Journal of Endodontics, 34, 514518. http://dx.doi.org/10.1016/j.joen.2008.02.042

[5] Moher, D., Liberati, A., Tetzlaff, J. and Altman, D.G. (2009) Preferred reporting items for systematic reviews and meta-analyses: The PRISMA statement. Annals of Internal Medicine, 151, 264-269.

http://dx.doi.org/10.7326/0003-4819-151-4-200908180-0 $\underline{0135}$

[6] Schulz, K.F., Altman, D.G. and Moher, D. (2010) CONSORT 2010 statement: Updated guidelines for reporting parallel group randomised trials. British Medical Journal, 340, 332. http://dx.doi.org/10.1136/bmj.c332

[7] Abdulwahab, M., Boynes, S., Moore, P., Seifikar, S., AlJazzaf, A., Alshuraidah, A., Zovko, J. and Close, J. (2009) The efficacy of six local anesthetic formulations used for posterior mandibular buccal infiltration anesthesia. Journal of the American Dental Association, 140, 1018-1024. http://dx.doi.org/10.14219/jada.archive.2009.0313

[8] Robertson, D., Nusstein, J., Reader, A., Beck, M. and McCartney, M. (2007) The anesthetic efficacy of articaine in buccal infiltration of mandibular posterior teeth. Journal of the American Dental Association, 138, 11041112. http://dx.doi.org/10.14219/jada.archive.2007.0324

[9] Kanaa, M.D., Whitworth, J.M., Corbett, I.P. and Meechan, J.G. (2006) Articaine and lidocaine mandibular buccal infiltration anesthesia: A prospective randomized double-blind cross-over study. Journal of Endodontics, 32, 296. http://dx.doi.org/10.1016/j.joen.2005.09.016

[10] Skjevik, Å.A., Haug, B.E., Lygre, H. and Teigen, K.
(2011) Intramolecular hydrogen bonding in articaine can be related to superior bone tissue penetration: A molecular dynamics study. Biophysical Chemistry, 154, 18-25. http://dx.doi.org/10.1016/j.bpc.2010.12.002

[11] Jaber, A., Whitworth, J.M., Corbett, I.P., Al-Baqshi, B., Kanaa, M.D. and Meechan, J.G. (2010) The efficacy of infiltration anaesthesia for adult mandibular incisors: A randomised double-blind cross-over trial comparing articaine and lidocaine buccal and buccal plus lingual infiltrations. British Dental Journal, 209, e16. http://dx.doi.org/10.1038/sj.bdj.2010.974

[12] Oliveira, P.C., Volpato, M.C., Ramacciato, J.C. and Ranali, J. (2004) Articaine and lignocaine efficiency in infiltration anaesthesia: A pilot study. British Dental Journal, 197, 45-46. http://dx.doi.org/10.1038/sj.bdj.4811422

[13] Kammerer, P.W., Palarie, V., Daublander, M., Bicer, C., Shabazfar, N., Brullmann, D. and Al-Nawas, B. (2012) Comparison of $4 \%$ articaine with epinephrine $(1: 100,000)$ and without epinephrine in inferior alveolar block for tooth extraction: Double-blind randomized clinical trial of anesthetic efficacy. Oral Surgery, Oral Medicine, Oral Pathology and Oral Radiology, 113, 495-499. http://dx.doi.org/10.1016/j.tripleo.2011.04.037

[14] Jung, I.Y., Kim, J.H., Kim, E.S., Lee, C.Y. and Lee, S.J. (2008) An evaluation of buccal infiltrations and inferior alveolar nerve blocks in pulpal anesthesia for mandibular first molars. Journal of Endodontics, 34, 11-13. http://dx.doi.org/10.1016/j.joen.2007.09.006

[15] National Patient Safety Agency (2004) Managing patients who are taking warfarin and undergoing dental treatment. http://www.nrls.npsa.nhs.uk/EasySiteWeb/getresource.ax d?AssetID $=60028 \&$

[16] Katyal, V. (2010) The efficacy and safety of articaine versus lignocaine in dental treatments: A meta-analysis. Journal of Dentistry, 38, 307. http://dx.doi.org/10.1016/j.jdent.2009.12.003 


\section{APPENDIX}

Table A1. A table outlining search strategies and number of hits per database.

\begin{tabular}{lc}
\multicolumn{1}{c}{ Electronic databases and search strategy } & No. hits per database \\
\hline Cochrane Central Register of Controlled Trials & 3 \\
Search Strategy: \\
articaine and dental and trial. \\
Database: Ovid MEDLINE(R) In-Process \& Other Non-Indexed Citations and Ovid MEDLINE(R) <1946 to \\
Present>, Ovid OLDMEDLINE(R) <1946 to 1965>, Embase Classic + Embase <1947 to 2013 March 29> \\
Search Strategy: \\
(articaine and dental and trial).mp. [mp = ti, ab, ot, nm, hw, kf, ps, rs, ui, an, sh, tn, dm, mf, dv, kw] (189) \\
remove duplicates (177) \\
Database: PubMed \\
Search Strategy: (articaine and dental and trial) \\
Query Translation: \\
(“carticaine” [MeSH Terms] OR “carticaine” [All Fields] OR “articaine”[All Fields]) AND (“dental clinics” [MeSH \\
Terms] OR (“dental” [All Fields] AND “clinics” [All Fields]) OR “dental clinics” [All Fields] OR “dental” [All \\
Fields]) AND (“clinical trials as topic” [MeSH Terms] OR (“clinical” [All Fields] AND “trials” [All Fields] AND \\
"topic” [All Fields]) OR “clinical trials as topic” [All Fields] OR “trial” [All Fields]) \\
Scirus \\
Search Strategy: (articaine and dental and trial). \\
Scopus \\
Search Strategy: (articaine and dental and trial). \\
Total
\end{tabular}

Databases last accessed $15^{\text {th }}$ June 2013.

Table A2. Data search exclusion criteria.

\begin{tabular}{cl}
\hline & Narratives with no original data \\
& Book chapters not reporting the original data source \\
Design & Studies not providing the raw data of the effect measures \\
& Studies not relating to anaesthesia of lower first molar teeth \\
& Studies not including the use of $2 \%$ lidocaine $1: 100,000$ adrenaline and $4 \%$ articaine $1: 100,000$ adrenaline \\
& Studies exclusively relating to children $<16$ years of age \\
\hline Data & Studies not reporting sample size \\
\hline
\end{tabular}

Table A3. Criteria for quality and the quality assessment of the included trials.

\begin{tabular}{|c|c|}
\hline & Criteria for assessing the quality of the included trials \\
\hline 1) Random Sequence Generation & $\begin{array}{l}\text { Adequate-Details on random generation satisfying CONSORT criteria. } \\
\text { Unclear-No details as to the process of randomization. } \\
\text { Inadequate-Assignment. }\end{array}$ \\
\hline $\begin{array}{l}\text { 2) Randomisation: Allocation } \\
\text { Concealment Mechanism }\end{array}$ & $\begin{array}{l}\text { Adequate_-Details on the Allocation Concealment Mechanism satisfying CONSORT criteria. } \\
\text { Unclear-No details as to the process of concealment mechanism. } \\
\text { Inadequate_-no concealment mechanism used. }\end{array}$ \\
\hline 3) Blinding of Operator & $\begin{array}{l}\text { Adequate-Specified operator adequately blinded. } \\
\text { Unclear-Blinding not specified. } \\
\text { Inadequate - the operator was aware of which groups the participants had been randomized. }\end{array}$ \\
\hline 4) Handling of Losses & $\begin{array}{l}\text { Adequate-information provided with regards to those participants who violated the protocol of the } \\
\text { study, dropped out or were withdrawn. } \\
\text { Unclear-No details within text. } \\
\text { Inadequate-numbers of participants lost with no information. } \\
\text { Not applicable. }\end{array}$ \\
\hline 5) Analysis for Losses & $\begin{array}{l}\text { Adequate-Information suggesting intention to treat analysis to include participant within trial } \\
\text { regardless of what had occurred. } \\
\text { Unclear-No details within text. } \\
\text { Inadequate-the approach as suggested by CONSORT was not utilised. } \\
\text { Not applicable. }\end{array}$ \\
\hline
\end{tabular}


Table showing the quality assessment of included trials

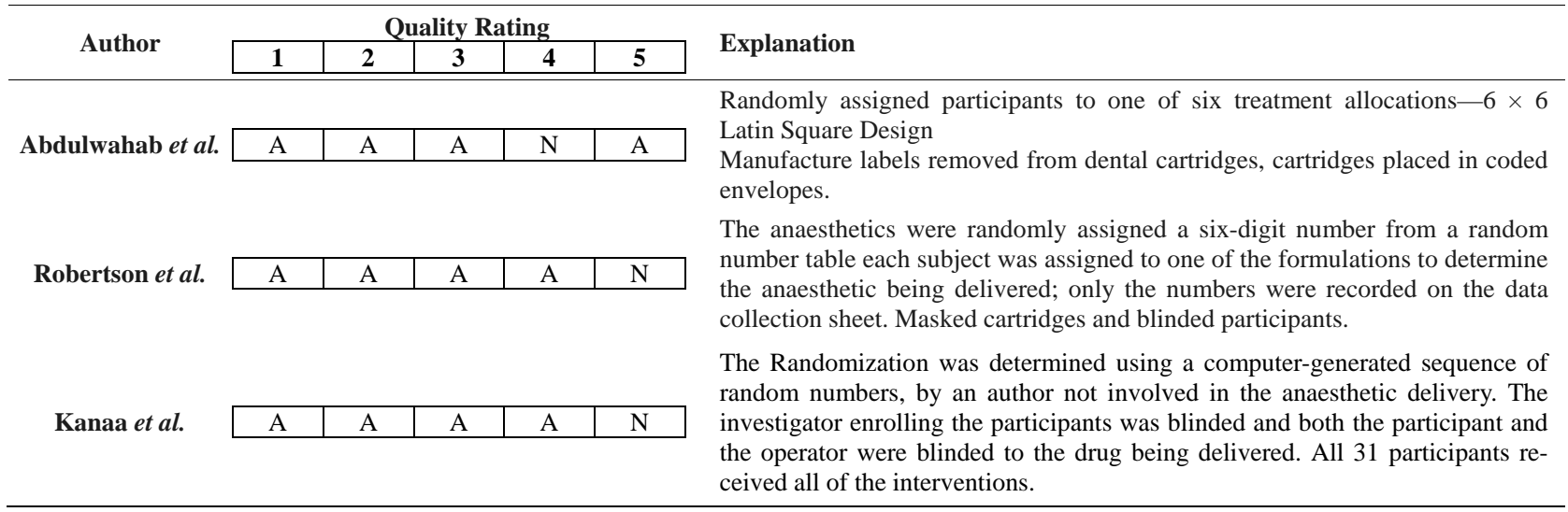

